\title{
Olefin polymerization over supported chromium oxide catalysts
}

\author{
Bert M. Weckhuysen*, Robert A. Schoonheydt \\ Centrum voor Oppervlaktechemie en Katalyse, Departement Interfasechemie, Katholieke Universiteit Leuven, \\ Kardinaal Mercierlaan 92, 3001, Heverlee, Belgium
}

\begin{abstract}
$\mathrm{Cr} / \mathrm{SiO}_{2}$ or Phillips-type catalysts are nowadays responsible for a large fraction of all polyethylene (HDPE and LLDPE) worldwide produced. In this review, several key-properties of $\mathrm{Cr} / \mathrm{SiO}_{2}$ catalysts will be discussed in relation to their polymerization characteristics. It will be shown how the polyolefin properties can be controlled via rational catalyst design. (C) 1999 Elsevier Science B.V. All rights reserved.
\end{abstract}

Keywords: Olefin polymerization; Chromium oxide catalysts; $\mathrm{Cr} / \mathrm{SiO}_{2}$

\section{Introduction}

The production of polyolefins such as high density polyethylene (HDPE), low density polyethylene (LDPE), linear low density polyethylene (LLDPE), and polypropylene (PP) is a multi-billion industrial activity. With the exception of LDPE, which is made by radical combination reactions at high temperature $\left(250-300^{\circ} \mathrm{C}\right)$ and pressure ( $>50 \mathrm{bar}$ ), all these polyolefins are produced by using either homogeneous or heterogeneous catalysts [1]. These catalysts always operate at relatively low temperature $\left(80-180^{\circ} \mathrm{C}\right)$ and pressure $(<50$ bar). Three classes of polymerization catalysts can be distinguished:

1. Phillips-type catalysts, which are composed of a chromium oxide supported on an amorphous material such as silica (e.g. $\mathrm{Cr} / \mathrm{SiO}_{2}$ );

\footnotetext{
*Corresponding author. Fax: +32-16-32-19-98; e-mail: bert.weckhuysen@agr.kuleuven.ac.be
}

2. Ziegler-Natta catalysts, which consist of a combination of titanium chloride and an alkylaluminum chloride, mostly supported on $\mathrm{MgCl}_{2}$ (e.g. $\mathrm{TiCl}_{3}-$ $\left.\mathrm{Al}\left(\mathrm{C}_{2} \mathrm{H}_{5}\right)_{3} / \mathrm{MgCl}_{2}\right)$; and

3 . the recently commercialized single site metallocene catalysts, which are bis-cyclopentadienyl derivatives of either $\mathrm{Zr}$, Hf or $\mathrm{Ti}$, in combination with methylaluminoxane (e.g. $\mathrm{Cp}_{2} \mathrm{ZrCl}_{2}$ $\left.[\mathrm{MeAlO}]_{n}\right)$.

Phillips-type catalysts, named after the company name of the inventors J.P. Hogan and R.L. Banks, are nowadays responsible for the commercial production of more than one third of all polyethylene sold worldwide. It is certainly this industrial importance, which has attracted the great deal of academic and industrial research [2-10]. Despite all these efforts, however, Phillips-type polymerization catalysts remain controversial, and still the same questions - often truly academic in nature - are asked since their discovery in the early 1950s [7]. These questions are: 
1. What is the oxidation state of the active site?

2. What is the exact polymerization mechanism? and

3. What is the molecular structure of the catalyst?

Although in the last two decades a lot of progress has been made in resolving these issues by applying advanced spectroscopic techniques, no unifying picture has yet been achieved [3]. This lack of agreement must be attributed to the following reasons:

1. Only a small fraction of the chromium centers are considered to be active. As a consequence, almost all the reported characterization results are not directly related to the active centers of the catalysts.

2. Phillips-type catalysts are often regarded as "monolithic"; i.e., treated if only one catalyst type/ composition is used. However, the catalyst structure is extremely sensitive towards different preparation and treatment conditions. As a consequence, the results of different research groups are difficult to compare. Rather, a whole battery of spectroscopic techniques have to be applied on the same set of catalysts to gather relevant information. In this respect, it is important to note the differences in sensitivity of different spectroscopic techniques towards surface Cr species.

3. Most published polymerization studies have been conducted on a vacuum line at $25^{\circ} \mathrm{C}$ and pressures lower than 1 bar. Such experiments, although interesting, are often far away from real industrial conditions. Therefore, such experiments are not always reliable indicators of the performances of a particular catalyst. There is clearly a need for in situ characterization studies which allow measurements as close as possible to real catalytic ones.

The aim of this review paper is to touch on the most important aspects of Phillips-type polymerization catalysts. However, no attempt will be given to cover the whole field, and in this respect, we refer to several excellent review papers, most notably the review paper of McDaniel published in 1985 [2]. For background, a general description of the Phillips polymerization process will be given. In the second section, the elementary steps in catalyst synthesis will be reviewed, while the third section gives an overview of the recent literature on catalyst characterization. In the final section, it will be shown how the polyolefin properties can be controlled via rational catalyst design.

\section{General description of the Phillips polymerization process}

The heart of the Phillips polymerization process is a supported chromium oxide catalyst, which is usually prepared by impregnation of a chromium oxide on a wide pore silica $[2,5]$. The impregnated material is subsequently heated in air at high temperature, cooled down, flushed with nitrogen, and stored under dry nitrogen until loaded in the polymerization reactor.

Chromium-based catalysts are able to polymerize olefins which have no branching closer than the 4position to the double bond and which contain no more than about eight carbon atoms. Thus, propylene, 1butene, 1-pentene, and 1-hexene are polymerized to branched, high molecular weight polymers ranging from solids to viscous liquids. From ethylene, a broad range of solid polymers are produced, which are characterized by a linear backbone without long-chain branching (HDPE). Copolymerization of ethylene with mostly $\mathrm{C}_{4}-\mathrm{C}_{8}$ olefins gives a branched polymer, in which the number of branches per molecule and the number of carbon atoms per branch depend on the amount and nature of the comonomer (LLDPE). It is important to note that chromium-based catalysts always produce a resin with a broad distribution of individual polymer molecules, each of which contributes to the overall properties of the resin. It is this molecular weight distribution (MWD) which determines the properties, such as melt viscosity and elasticity, impact resistance, and environmental stress crack resistance. Besides molecular weight distribution, the amount, type and pattern of branching also influences the properties of the resin.

The success of the Phillips polymerization process originates from its diversity. Phillips catalysts are able to make more than 50 different types of polyethylene, and a whole battery of chromium-based catalysts are developed, each of which are able to produce a different type of HDPE or LLDPE [4]. Thus, the critical resin parameters are determined by the catalyst performances, and the different industrial companies are able to control their resin properties via catalyst design.

The polymerization of ethylene can be done over a relatively broad range of temperatures, however, the commercial temperatures range between $65^{\circ} \mathrm{C}$ and $180^{\circ} \mathrm{C}$. The relative rate of termination of the poly- 
ethylene chain determines the average chain length; i.e., the molecular weight (MW) of the polyethylene. Another important indicator is the melt index (MI). The MI is a measure of the molten polymer fluidity, and is inversely related to the MW. In the case of the reaction temperature, it is found that a higher temperature results in a higher relative termination rate, and as a consequence, in a higher MI and lower MW. The ethylene pressure is also an important factor, and is usually kept between 20 and 30 bar. In general, the higher the ethylene pressure in the polymerization reactor, the higher the MW of the produced polyethylene.

There are three different industrial modes of operation for the Phillips polymerization process [5,10]:

1. The solution process uses an inert hydrocarbon that dissolves the polymer as it is formed. The solvent may consist of a cycloparaffin, such as cyclohexane. Both monomer and polymer remain in the solution during the reaction while the finely-divided catalyst is maintained in suspension by agitation. Reaction temperatures range from $125^{\circ} \mathrm{C}$ to $175^{\circ} \mathrm{C}$, and reaction pressures from 20 to 30 bar. The reactor product is withdrawn and the monomer evaporated. The suspended catalyst is then removed by filtration, and the solvent is evaporated from the filtrate.

2. In the slurry process a liquid dispersant is used. This solvent is paraffinic in nature (e.g. $n$-pentane), and keeps both catalyst and polymer in suspension during polymerization. The reaction temperature is held below $110^{\circ} \mathrm{C}$ in order to prevent dissolution of the polymer. The slurry process is conducted in loop reactors, and is generally known as the PHILLIPS PARTICLE FORM ${ }^{\circledR}$ process. This process is worldwide licensed by Phillips Petroleum. Its name originates from the fact that during polymerization, the catalyst breaks up, and each catalyst particle forms a polymer particle several thousand times larger than itself. Because of the high catalytic activity, the catalyst residue in the polymer is insignificant. Recent studies using atomic force microscopy have shown that the catalyst undergoes continuous fragmentation during the formation of polyethylene with the larger fragments being pushed out toward the surface where the fragmentation continues [11].

3. The gas phase process, which does not require any solvent or dispersant is generally known as the
UNIPOL ${ }^{\circledR}$ process, and is licensed by union carbide. Gaseous ethylene, eventually together with a comonomer, such as 1-hexene, and the catalyst are reacted in a fluidized bed reactor at temperatures and pressures at around $100^{\circ} \mathrm{C}$ and $20 \mathrm{bar}$, respectively. The gas phase process has the advantage of eliminating the cost of supplying and recycling the solvent or dispersant. However, heat transfer rates are lower than in the particle form process, resulting in lower production rates per unit volume of reactor.

\section{Catalyst synthesis}

Phillips polymerization catalysts can be based either on organochromium compounds or on chromium oxides. The first type is made by calcining a high surface area support, and then depositing an organochromium compound, such as chromocene, onto it anhydrously. The calcination treatment partially dehydroxylates the surface, leaving mostly isolated hydroxyl groups, which can then react with the organochromium compound to attach the $\mathrm{Cr}$ to the carrier through an oxide bond. It is important to notice that one or more ligands may still remain attached to the $\mathrm{Cr}$. In the second family of catalysts, a chromium compound is impregnated from aqueous or non-aqueous solutions onto a support. Various chromium compounds, such as oxides, sulfates, acetates, etc. can be used. After the support and chromium compound are combined, and sufficiently dried, the catalyst is activated in dry air at high temperatures. Somewhere around $200^{\circ} \mathrm{C}$, an esterification reaction takes place between $\mathrm{CrO}_{3}$ and the hydroxyl groups of the support to yield a surface chromate and/or polychromate species. This material is catalytically inactive, and further calcination at higher temperature is necessary. This suggests that neighbouring hydroxyl groups may interfere with the polymerization process. The calcination step is done in a fluidized bed at temperatures between $500^{\circ} \mathrm{C}$ and $1000^{\circ} \mathrm{C}$. After calcination, the catalyst is cooled down, and flushed with nitrogen to remove the air.

The chromium content in the catalyst varies from a few hundredths of a wt $\%$ to several wt $\%$, but typical Cr loadings are $0.2 \mathrm{wt} \%$ for gas-phase processes (UNIPOL ${ }^{\mathbb{R}}$ ) and $1 \mathrm{wt} \%$ for slurry processes (PHILLIPS PARTICLE FORM ${ }^{\circledR}$ ). However, most probably 
only a small fraction of the chromium is active in ethylene polymerization. Indeed, detailed experiments have shown that the activity per chromium atom reaches a maximum near a $\mathrm{Cr}$ loading of $0.01 \mathrm{wt} \%$.

The most suitable support for both types of catalysts is a wide-pore silica, although other supports, such as alumina, silica-alumina, aluminophosphates, and silica-titania, are also used. The hydroxyl groups of these supports can be replaced by a halide, such as fluoride. For example, supports, such as alumina, become much more active when they are fluorided. Other ways to eliminate the number of surface hydroxyl groups are calcination in $\mathrm{CO}, \mathrm{COS}$ or $\mathrm{CS}_{2}$. It is also important to stress here that the physical properties of the support, such as porosity, strongly influence both the catalytic activity and polymer properties. It seems that there is a critical pore diameter below which almost no polyethylene can be formed.

\section{Catalyst characterization}

\subsection{Hydrated catalyst}

Hydrated $\mathrm{Cr} / \mathrm{SiO}_{2}$ polymerization catalysts are covered by a thin water film and the hydroxyl population of the silica is subject to $\mathrm{pH}$ dependent equilibria reactions (3):

$$
\begin{aligned}
& \mathrm{Si}-\mathrm{OH}_{2}^{+} \leftrightarrow \mathrm{Si}-\mathrm{OH}+\mathrm{H}_{\mathrm{s}}^{+} \\
& \mathrm{Si}-\mathrm{OH} \leftrightarrow \mathrm{Si}-\mathrm{O}^{-}+\mathrm{H}_{\mathrm{s}}^{+} \\
& \mathrm{H}_{\mathrm{s}}^{+} \leftrightarrow \mathrm{H}^{+}
\end{aligned}
$$

where $\mathrm{H}_{\mathrm{s}}^{+}$and $\mathrm{H}^{+}$represent the surface and solution proton, respectively; $K_{1}=\left([\mathrm{Si}-\mathrm{OH}] *\left[\mathrm{H}_{\mathrm{s}}^{+}\right]\right) /$ $\left[\mathrm{Si}-\mathrm{OH}_{2}^{+}\right] ; K_{2}=\left(\left[\mathrm{Si}-\mathrm{O}^{-}\right] *\left[\mathrm{H}_{\mathrm{s}}^{+}\right]\right) /[\mathrm{Si}-\mathrm{OH}] . \quad$ The iso-electric point, IEP, defined as $\left(\mathrm{p} K_{1}+\mathrm{p} K_{2}\right) / 2$, represents the $\mathrm{pH}$ at which the surface of the silica has a net zero charge, and varies between 1 and 2 for sol-gel prepared silicas and 3-4 for aerosil-based silicas. The lower the IEP of the silica, the more the equilibria of the reactions (1)-(3) are driven to the right. The higher the $\mathrm{H}^{+}$concentration near the surface, the more dichromate (polychromate) is formed, as confirmed by spectroscopic means [12,13].

When the $\mathrm{CrO}_{3}$ loading increases two effects come into play:
1. the $\mathrm{pH}$ near the surface is lowered due to the presence of $\mathrm{Cr}$, and decreases with increasing $\mathrm{Cr}$ loading, and

2. the dispersion depends on the available surface area as well as availability of reactive surface hydroxyl groups.

Both factors influence the chemistry of Cr in the same direction i.e., towards the formation of surface polychromates $[3,13]$.

\subsection{Calcined catalyst}

Upon heating of $\mathrm{Cr} / \mathrm{SiO}_{2}$ catalysts in air, the water molecules adsorbed on silica and around dichromates (polychromates) are removed. The formed dehydrated chromium oxide species do not decompose into $\mathrm{O}_{2}$ and $\mathrm{Cr}_{2} \mathrm{O}_{3}$ (like the pure compounds), at least for low Cr loadings, but are anchored by an esterification reaction with the hydroxyl groups of silica, resulting in the formation of surface $\mathrm{Cr}$ species. Evidence for this anchorage reaction comes from:

1. infrared spectroscopy [14-16] indicating the consumption of hydroxyl groups;

2. experiments with $\mathrm{CrO}_{2} \mathrm{Cl}_{2}$ and silica, which show the release of $\mathrm{HCl}$ and the reverse reaction of dry $\mathrm{HCl}$ with calcined $\mathrm{Cr} / \mathrm{SiO}_{2}$ with release of $\mathrm{CrO}_{2} \mathrm{Cl}_{2}$ vapor [17-20]; and

3. the exothermal peak in differential thermal analysis curves around $250^{\circ} \mathrm{C}$, which is ascribed to this esterification reaction [21].

The molecular structure of the anchored $\mathrm{Cr}^{6+}$ is a strong point of discussion in the literature, and several molecular structures (monochromate, dichromate, polychromate, etc.) are proposed either on the basis of direct or indirect measurements [3]:

1. Many researchers have measured the change in hydroxyl population of a silica surface on anchoring of chromium: a monochromate species should react with two hydroxyls per $\mathrm{Cr}$, while dichromate displaces only one per $\mathrm{Cr}$. However, the results from this approach were contradictory. Hogan [8,9] and McDaniel [1720] concluded that $\mathrm{CrO}_{3}$ attaches mainly as monochromate, while Zecchina et al. [14] and Krauss and Stach [22] reported that dichromate was the dominant species. Others have tried to correlate the geometry of chromate and dichromate with models of amorphous 
supports [2,3]. Although they show that dichromate is favored on silica, these kind of studies are too uncertain due to the lack of information about silica surfaces and the surfaces of amorphous supports in general.

2. Direct information about the molecular structure can be found by the application of a combination of diffuse reflectance spectroscopy and Raman spectroscopy [3,13,23-27]. By applying both spectroscopic techniques on an industrial pyrogenic (Cab-O-Sil, $\left.300 \mathrm{~m}^{2} / \mathrm{g}\right)$ and a laboratory sol-gel $\left(700 \mathrm{~m}^{2} / \mathrm{g}\right)$ $0.1 \mathrm{wt} \% \mathrm{Cr} / \mathrm{SiO}_{2}$ catalysts, we found that the molecular structure changed from monochromate on the Cab-O-Sil material to a mixture of monochromate and dichromate (polychromate) on the sol-gel prepared material. This difference can be explained by the difference in IEP between the silicas. The Cab-O-Sil silica with an IEP of 4 favors the formation of chromate in hydrated material, and this species is upon calcination directly anchored as a chromate species onto the surface. In strong contrast, the sol-gel prepared silica has an IEP of 1-2. This silica favors the formation of dichromate (polychromate) in the hydrated material, which is then anchored onto the silica surface upon calcination. At higher Cr loadings, dichromates (polychromates) are always the dominant species. Thus, both the silica type and the Cr loading have a strong influence on the molecular structure of $\mathrm{Cr} / \mathrm{SiO}_{2}$ catalysts. These differences also explain why the data in the literature are sometimes difficult to compare and only by a combination of different spectroscopic techniques can detailed molecular-level information be obtained [3].

In addition to the chromates/polychromates, $\mathrm{Cr}^{5+}$ ions and $\mathrm{Cr}_{2} \mathrm{O}_{3}$-clusters can also be formed on $\mathrm{Cr} / \mathrm{SiO}_{2}$ catalysts, and their relative amount is loading and treatment dependent. Although $\mathrm{Cr}^{5+}$ is generally considered to possess square pyramidal or distorted tetrahedral coordination [28-31], some researchers insist that it involves a combination of $\mathrm{Cr}^{6+}$ and $\mathrm{Cr}^{3+}$ (i.e., a Zener double exchange system) [32-34]. Detailed electron spin resonance studies of supported $\mathrm{Cr}$ and of $\mathrm{Cr}^{53}$ enriched supported $\mathrm{Cr}$ systems [30,35-38] reject this hypothesis, and show that $\mathrm{Cr}^{5+}$ is present as an isolated paramagnetic ion.

$\mathrm{Cr}_{2} \mathrm{O}_{3}$-formation is the most pronounced on $\mathrm{Cr}$ / $\mathrm{SiO}_{2}$ catalysts with high $\mathrm{Cr}$ loadings, and after heating at high temperature with a high heating rate. Thus, as the chromium loading increases, almost all $\mathrm{Cr}$ is stabilized in the hexavalent state until a certain saturation coverage is reached. Beyond this limit, excess $\mathrm{Cr}$ is converted to $\mathrm{Cr}_{2} \mathrm{O}_{3}$.

\subsection{Reduced and active catalyst}

Several spectroscopic and chemical techniques have shown that $\mathrm{Cr}^{2+}$ is the main species in $\mathrm{Cr} /$ $\mathrm{SiO}_{2}$ catalysts after $\mathrm{CO}$ reduction. In this respect, infrared spectroscopy has shown to be a powerful technique due to its ability to discriminate between different surface $\mathrm{Cr}^{2+}$ species [39-54]. Three families of anchored $\mathrm{Cr}^{2+}$-ions have been singled out (labeled as A, B and C) after chemisorption of CO. These three species differ in their degree of coordinative unsaturation $(\mathrm{A}<\mathrm{B}<\mathrm{C})$, and consequently in their propensity to react $(\mathrm{A}>\mathrm{B}>\mathrm{C})$.

To our knowledge, the structure of an active polymerization catalyst is still unknown. As a consequence, there is a need for in situ characterization studies under conditions as close as possible to polymerization conditions. However, the continuous polymerization and catalyst fragmentation will make this task difficult, if not impossible.

\section{Controlling polyolefin properties via catalyst design}

The activity of Phillips-type polymerization catalysts is very sensitive towards catalyst preparation and composition [2]. It is this property which is exploited by industrial scientists to design a specific catalyst towards the synthesis of a polymer with well-defined properties $[4,6]$. In general, one can intervene at two different levels, which are somewhat related; i.e., the catalyst composition and [2] the physicochemical properties of the support.

\subsection{Catalyst composition}

Although $\mathrm{SiO}_{2}$ is the support of choice for the preparation of active polymerization catalysts, $\mathrm{Al}_{2} \mathrm{O}_{3}, \mathrm{AlPO}_{4}, \mathrm{SiO}_{2} \cdot \mathrm{Al}_{2} \mathrm{O}_{3}$ and $\mathrm{ZrO}_{2}$ can also serve as a support. In the case of $\mathrm{Cr} / \mathrm{Al}_{2} \mathrm{O}_{3}$ catalysts, the polymerization activity is one order of magnitude lower than for the $\mathrm{Cr} / \mathrm{SiO}_{2}$ system. Furthermore, the 
$\mathrm{Cr} / \mathrm{Al}_{2} \mathrm{O}_{3}$ catalyst produces polyethylene with a high MW because of a much lower termination rate. The addition of fluoride to the same catalyst may substantially increase its polymerization activity. In this respect, it is important to note that $\mathrm{TiO}_{2}$ is not a good support for Cr-based polymerization catalysts. However, the addition of small amounts of $\mathrm{TiO}_{2}$ has shown to drastically alter the polymerization activity and termination rate of $\mathrm{Cr} / \mathrm{SiO}_{2}$ catalysts [55-59]. These differences are explained in terms of the formation of $\mathrm{Si}-\mathrm{O}-\mathrm{Ti}-\mathrm{O}-\mathrm{Cr}$ bonds, which may have an effect on the electronic properties of the attached Cr. Catalysts prepared by coating $\mathrm{SiO}_{2}$ with a layer of $\mathrm{TiO}_{2}$ up to 5-6 wt \% are known to produce polyethylene with a broader MWD and higher MI. In the case of coprecipitation of hydrous $\mathrm{TiO}_{2}$ and $\mathrm{SiO}_{2}$ gels, polyethylene with a narrower MWD is obtained.

\subsection{Physicochemical properties of supports}

The catalyst support not only acts as a dispersing agent for the active $\mathrm{Cr}$ centers, but its properties have also a dramatic effect on the polymer characteristics. The most important factors are pore volume, pore size and surface area. High pore volume $\mathrm{Cr} / \mathrm{SiO}_{2}$ catalysts are known to produce polymers with a low MW and high MI. In addition, Cr-based polymerization catalysts prepared from silicas with small pores are always catalytically inferior, and therefore, the industrial silicas of choice have an average pore size diameter from 50 to above $200 \AA$. In this respect, it is important to note that polyethylene with a low MW can be produced with silicas with a larger pore size.

Another important characteristic of the support is its hydroxyl population. As discussed above, the presence of hydroxyl groups has a negative effect on the catalytic performances of $\mathrm{Cr} / \mathrm{SiO}_{2}$ catalysts, and several procedures are reported in literature to decrease their amount. The most convenient way is increasing the calcination temperature, and it is known that a higher calcination temperature results in both an increase in the polymerization activity, and the MI of the polymer. Other alternatives are the use of other supports, and treating the catalyst at high temperatures in $\mathrm{CO}, \mathrm{COS}$ or $\mathrm{CS}_{2}$. Finally, it is important to note that the silica support must be fragmentable during ethylene polymerization, but still be strong enough to withstand the catalyst preparation and treatment. Thus, special preparation methods were developed in the past for the industrial production of $\mathrm{SiO}_{2}$ used for the preparation of Cr-based polymerization catalysts.

Summarizing, the production of the type of silica and its treatment history are crucial for both the catalyst activity, and the type of polyethylene produced. Very recently, McDaniel et al. [60] reported on the effect of alkali metal doping on the polymerization performance and catalyst stability. Commercial silicas begin to sinter at around $900^{\circ} \mathrm{C}$, which causes a loss of surface area and porosity, and thus a decrease in catalyst activity. Alkali metal doping can promote sintering of silica, and commercial silica manufacturers take great care to wash, or ion exchange, out the last traces of residual sodium ions from their polymerization grade silicas.

\section{Conclusions}

Cr-based catalysts, mainly $\mathrm{Cr} / \mathrm{SiO}_{2}$ and $\mathrm{Cr} / \mathrm{Ti} / \mathrm{SiO}_{2}$ catalysts, are worldwide used for the production of a whole variety of HDPE and LLDPE in the reknown Phillips polymerization process. The success of this process originates from its diversity, and more than 50 different types of polyethylene are made by $\mathrm{Cr}$-based catalysts. Because of the complex surface chemistry of $\mathrm{Cr}$, different $\mathrm{Cr}$ species can be present on the catalyst surface, depending on the support type and $\mathrm{Cr}$ loading. It is the interplay between the different $\mathrm{Cr}$ species, which are crucial in controlling the polymer properties. Although the structure of an active polymerization catalyst is still unknown, it is anticipated that coordinatively unsaturated $\mathrm{Cr}^{2+}$ species are involved in the initial polymerization steps. The authors hope that some of the unresolved catalytic questions can be tackled by studying the recently developed surface science model for the Phillips catalyst in great detail [61].

\section{Acknowledgements}

B.M.W. acknowledges the Belgian National Fund for Scientific Research for a position as postdoctoral research fellow. 


\section{References}

[1] J.C. Stevens, Stud. Surf. Sci. Catal. 101 (1996) 11.

[2] M.P. McDaniel, Adv. Catal. 33 (1985) 47.

[3] B.M. Weckhuysen, I.E. Wachs, R.A. Schoonheydt, Chem. Rev. 96 (1996) 3327.

[4] M.P. McDaniel, Ind. Eng. Chem. Res. 27 (1988) 1559.

[5] A. Clark, Catal. Rev. 3 (1969) 145.

[6] M.P. McDaniel, Handbook of Heterogeneous Catalysis, in: G. Ertl, H. Knozinger, J. Weitkamp (Eds.), vol. 5, VCH, Verlagschaft, 1997, p. 2400.

[7] J.P. Hogan, R.L. Banks, Belg. Pat. 530617 (1955).

[8] J.P. Hogan, J. Polym. Sci. 8 (1970) 2637.

[9] J.P. Hogan, in: B.E. Leach (Ed.), Appl. Ind. Catal. 1 (1983) 149.

[10] F.J. Karol, F.I. Jacobson, Stud. Surf. Sci. Catal. 25 (1986) 323.

[11] V.J. Ruddick, J.P.S. Badyal, J. Phys. Chem. B 101 (1997) 1791.

[12] G. Deo, I.E. Wachs, J. Phys. Chem. 95 (1991) 5889.

[13] B.M. Weckhuysen, R.A. Schoonheydt, J.M. Jehng, I.E. Wachs, S.J. Cho, R. Ryoo, S. Kijlstra, E. Poels, J. Chem. Soc., Faraday Trans. 91 (1995) 3245.

[14] A. Zecchina, E. Garrone, G. Ghiotti, C. Morterra, E. Borello, J. Phys. Chem. 79 (1975) 966.

[15] M. Nishimura, J.M. Thomas, Catal. Lett. 19 (1993) 33.

[16] M.A. Vuurman, I.E. Wachs, D.J. Stufkens, A. Oskam, J. Mol. Catal. 80 (1993) 209.

[17] M.P. McDaniel, J. Catal. 67 (1981) 71.

[18] M.P. McDaniel, J. Catal. 76 (1982) 17.

[19] M.P. McDaniel, J. Catal. 76 (1982) 29.

[20] M.P. McDaniel, J. Catal. 76 (1982) 37.

[21] C. Groeneveld, P.P.M.M. Wittgen, A.M. Kersbergen van, P.L.M. Hestrom, C.E. Nuijten, G.C.A. Schuit, J. Catal. 59 (1979) 153.

[22] H.L. Krauss, H.Z. Stach, Anorg. Allg. Chem. 414 (1975) 97.

[23] D.S. Kim, J.M. Tatibouet, I.E. Wachs, J. Catal. 136 (1992) 209.

[24] D.S. Kim, I.E. Wachs, J. Catal. 142 (1993) 166.

[25] M.A. Vuurman, D.J. Stufkens, A. Oskam, J.A. Moulijn, F. Kapteijn, J. Mol. Catal. 60 (1990) 83.

[26] M.A. Vuurman, I.E. Wachs, J. Phys. Chem. 96 (1992) 5008.

[27] M.A. Vuurman, F.D. Hardcastle, I.E. Wachs, J. Mol. Catal. 84 (1993) 193

[28] D.E. O'Reilly, D.S. MacIver, J. Phys. Chem. 66 (1962) 276.

[29] D.E. O'Reilly, F.D. Santiago, R.G. Squires, J. Phys. Chem. 73 (1969) 3172.

[30] D. Cordischi, M.C. Campa, V. Indovina, M. Occhiuzzi, J. Chem. Soc., Faraday Trans. 90(1) (1994) 207.

[31] D. Cordischi, V. Indovina, M. Occhiuzi, J. Chem. Soc., Faraday Trans. 87(20) (1991) 3443.
[32] A. Ellison, J. Chem. Soc., Faraday Trans. 180 (1984) 2581.

[33] R. Spitz, J. Catal. 35 (1974) 345.

[34] R. Spitz, A. Revillon, A. Guyot, J. Catal. 35 (1974) 335.

[35] K. Kohler, C.W. Shlapfer, A. Zelewsky von, J. Nickl, J. Engweiler, A. Baiker, J. Catal. 143 (1993) 201.

[36] D. Cordishi, V. Indovina, M. Occhiuzzi, Appl. Surf. Sci. 55 (1992) 233.

[37] B.M. Weckhuysen, L.M. De Ridder, P.J. Grobet, R.A. Schoonheydt, J. Phys. Chem. 99 (1995) 320.

[38] B.M. Weckhuysen, R.A. Schoonheydt, F.E. Mabbs, D. Collison, J. Chem. Soc., Faraday Trans. 92 (1996) 2431.

[39] A. Zecchina, E. Garrone, G. Ghiotti, C. Morterra, E. Borello, J. Phys. Chem. 79 (1975) 972.

[40] A. Zecchina, E. Garrone, G. Ghiotti, C. Morterra, E. Borello, J. Phys. Chem. 79 (1975) 978.

[41] A. Zecchina, E. Garrone, G. Ghiotti, C. Morterra, E. Borello, J. Phys. Chem. 79 (1975) 984.

[42] A. Zecchina, G. Spoto, G. Ghiotti, E. Garrone, J. Mol. Catal. 86 (1994) 423.

[43] P.A. Zielinski, I.G. Dalla Lana, J. Catal. 137 (1992) 368.

[44] P.A. Zielinski, J.A. Szymura, I.G. Dalla Lana, Catal. Lett. 13 (1992) 331.

[45] G. Ghiotti, E. Garrone, A. Zecchina, J. Mol. Catal. 46 (1988) 61.

[46] G. Ghiotti, E. Garrone, A. Zecchina, J. Mol. Catal. 65 (1991) 73.

[47] C.S. Kim, S.I. Woo, J. Mol. Catal. 73 (1992) 249.

[48] B. Rebenstorf, R. Larsson, Z. Anorg. Allg. Chem. 478 (1981) 119.

[49] B. Rebenstorf, R. Larsson, J. Catal. 84 (1983) 240.

[50] B. Rebenstorf, J. Mol. Catal. 38 (1986) 355.

[51] B. Rebenstorf, J. Mol. Catal. 56 (1989) 170.

[52] B. Rebenstorf, J. Catal. 117 (1989) 71.

[53] M. Schram-Marth, A. Wokaun, A. Baiker, J. Catal. 138 (1992) 306.

[54] G. Spoto, S. Bordiga, E. Garrone, G. Ghiotti, A. Zecchina, J. Mol. Catal. 74 (1992) 175.

[55] T.J. Pullukat, R.E. Hoff, M. Shida, J. Polym. Sci. Polym. Chem. Ed. 18 (1980) 2857.

[56] S.J. Conway, J.W. Falconer, C.H. Rochester, J. Chem. Soc., Faraday Trans. 185 (1989) 71.

[57] S.J. Conway, J.W. Falconer, C.H. Rochester, G.W. Downs, J. Chem. Soc., Faraday Trans. 185 (1989) 1841.

[58] M.P. McDaniel, M.B. Welch, M.J. Dreiling, J. Catal. 82 (1983) 118.

[59] J.M. Jehng, I.E. Wachs, B.M. Weckhuysen, R.A. Schoonheydt, J. Chem. Soc., Faraday Trans. 91 (1995) 953.

[60] M.P. McDaniel, D.R. Witt, E.A. Benham, J. Catal. 176 (1998) 344.

[61] P.C. Thüne, C.P.J. Verhagen, M.J.G. van den Boer, J.W. Niemandsverdriet, J. Phys. Chem. B 101 (1997) 8559. 